\title{
Biocomposites based on poly(lactic acid)/willow-fiber and their injection moulded microcellular foams
}

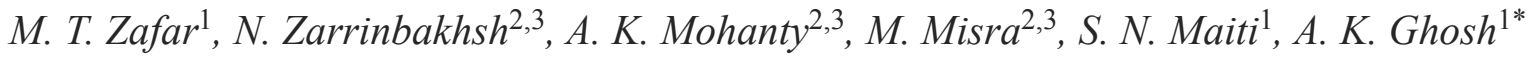 \\ ${ }^{1}$ Centre for Polymer Science and Engineering, Indian Institute of Technology Delhi, 110016 New Delhi, India \\ ${ }^{2}$ Bioproducts Discovery and Development Centre, Department of Plant Agriculture, Crop Science Building, University of \\ Guelph, Guelph, ON, N1G 2W1, Canada \\ ${ }^{3}$ School of Engineering, Thornbrough Building, University of Guelph, Guelph, ON, N1G 2W1, Canada
}

Received 29 July2015; accepted in revised form 28 September 2015

\begin{abstract}
Natural fiber reinforced biocomposites have recently attracted many researchers because of their biodegradability, cost effectiveness and ecofriendliness. The present study investigates the properties of willow-fiber reinforced poly(lactic acid) based composites and their foam processability. Microcellular foams of the composites were prepared by foam injection moulding using nitrogen gas as the blowing agent. The effects of willow-fiber addition on the morphology, mechanical properties, thermal stability, crystallization, and heat deflection temperature (HDT) were studied. At 30 weight percent [wt $\%$ ] willow-fiber content, unfoamed composites showed good improvement in specific tensile and flexural moduli. Addition of willow-fiber increased crystallinity and the rate of crystallization and yielded narrow crystallite size distribution as observed by differential scanning calorimetry (DSC). Scanning electron microscopy (SEM) results of the foamed composites revealed that increase in willow-fiber content caused smaller average cell size and higher cell density. Specific notch impact strength of foamed composites at both 20 and $30 \mathrm{wt} \%$ willow-fiber content showed increasing trend compared to that of their unfoamed counterparts.
\end{abstract}

Keywords: biopolymers, biocomposites, reinforcements, foam injection moulding, microcellular foam

\section{Introduction}

Poly(lactic acid) (PLA), a biobased polymer, has properties comparable to that of petroleum based plastics but has limited commercial applications due to its higher cost and narrow processing window [1-4]. As the main drawbacks associated with PLA are low toughness, low impact strength, low crystallinity, and slower crystallization rate: preparation of biocomposites using natural fibers followed by foaming can be an efficient way to overcome these drawbacks of PLA. Nowadays technology based on the reinforcement of the polymer matrix using natural fibers is focusing on creating lightweight materials with lower cost, higher modulus and higher crystallinity. However, this cost effectiveness is achieved at the loss of other valuable properties as the incorporation of cellulosic natural fibers makes the polymer matrix brittle and also decreases the impact strength [5]. As a possible solution, foaming of these biocomposites is expected to improve the impact strength and toughness.

Foamed materials show specific properties, such as lightweight, low thermal conductivity, high surface area, etc. There are several techniques available for creating porous structure in the polymer matrix e.g. - salt leaching, freeze drying, gas foaming, etc. Among all, gas foaming is the simplest and most commonly used method to prepare porous polymeric materials [6]. During the gas foaming process, initially the gas is incorporated inside the polymer

\footnotetext{
${ }^{*}$ Corresponding author, e-mail: anupkghosh@gmail.com

(C) BME-PT
} 
matrix which later on releases and leaves micro cells inside the matrix. Polymeric foams can be open or close cell type. In open cell structure, the neighboring cells are interconnected while in closed cell structure all cells are well separated by cell walls. Open cell foams are generally more flexible than closed-cell foams. The blowing agents used for the foaming are either physical or chemical blowing agents. Chemical blowing agents undergo thermal decomposition reactions and evolve the foaming gases while physical blowing agents are themselves the gases [7]. Foaming reduces the brittleness and increases the impact resistance of the biocomposites along with significant improvement in the expansion ratio and weight reduction. The high expansion ratio of the foamed biocomposites helps in reducing the material cost in mass production of plastic parts. The expansion ratio, which is a function of the cell-size and cell-density, is the crucial factor in controlling the mechanical performance of the foamed biocomposites. The increase in cell-size beyond a limit causes reduction in the mechanical properties. Therefore the optimization between the cell-size i.e. the expansion ratio and the mechanical properties is a challenging task and offers a huge potential for the research activities.

The microcellular injection moulding process utilizes physical blowing agents - mainly $\mathrm{N}_{2}$ or $\mathrm{CO}_{2}$. These gases are used as supercritical fluid to produce microcells. There are a lot of challenges in working with microcellular injection moulding process because of the dynamic nature of the procedure. Most of the time it becomes difficult to get the desired cell morphology (i.e. high cell density and small average cell size) and often large and non-uniform cell size results due to the lack of control on the process [8]. Willow biomass is abundantly found in moist soils in cold temperate regions of the northern hemisphere. It is an energy crop which grows very fast and harvested using advanced agricultural tools. The easy availability, abundance and fast growing capability makes the willow-fiber most prominent cellulosic filler to meet the growing demand of the biocomposites in commodity and industrial applications. Even then the area of biodegradable polymer biocomposites based on willow-fiber is almost unexplored. Therefore, the present research work unravels the potential of the willow-fiber as a natural fiber reinforcement as well as heterogeneous nucleating agent in the foaming process of biocomposites.
The present research work comprises of two stages: 1) Processing of biocomposites using extruder and 2) injection molding of the prepared biocomposites by two separate processes - one by conventional injection molding without foaming module and other with the foaming module on the same injection molding machine to prepare unfoamed and foamed samples respectively, which were further characterized by various techniques.

\section{Experimental}

\subsection{Materials}

Poly(lactic acid) (PLA) 3001D was procured from NatureWorks ${ }^{\circledR}$ LLC, USA. As per the material data sheet it had specific gravity of 1.24 and melt flow index of $22 \mathrm{~g} / 10 \mathrm{~min}\left(210^{\circ} \mathrm{C}, 2.16 \mathrm{~kg}\right)$. The glass transition temperature was $60-63{ }^{\circ} \mathrm{C}$ and melting temperature was $170^{\circ} \mathrm{C}$. Willow-fiber (biomass-willow) were harvested in December 2009 at the Guelph Turf Grass Institute (GTI), Guelph, ON, Canada, and pelletized at the Crosswood Farm without using any additive and was used as received.

\subsection{Composite processing}

Before processing, PLA was dried at $70^{\circ} \mathrm{C}$ under vacuum for 24 hours. Willow-fiber was dried by keeping them inside the hot air drier at $80^{\circ} \mathrm{C}$ for 48 hours. PLA and willow-fiber were then compounded in a co-rotating twin screw extruder from Lab Tech Engineering Company Ltd., Thailand, with $L / D=32$, and screw diameter $=26 \mathrm{~mm}$. The screw speed was $100 \mathrm{rpm}$. PLA and willow-fiber were fed through different feeders (feeder-1 and feeder-2) and the feeder speeds were calibrated in order to get the desired percentage of PLA and willow-fiber. The extruder temperature was set in accordance with predetermined temperature profile (zone 1-zone 8: $\left.140,160,180,190,200,200,200,200^{\circ} \mathrm{C}\right)$. After extrusion, composite strands were chopped into small pellets by a pelletizer and dried in a vacuum oven for 24 hours at $80^{\circ} \mathrm{C}$. PLA/willow-fiber composites at willow-fiber content of 20 and $30 \mathrm{wt} \%$ and virgin PLA as a reference material were extruded.

\subsection{Preparation of unfoamed and foamed samples}

Samples of the composites, extruded PLA and virgin PLA were injection moulded using an Arburg Allrounder $370 \mathrm{~S}, 77$ tons injection moulding machine equipped with Mucell ${ }^{\circledR}$ module from Trexel Inc. 
Table 1. Processing conditions used for the Injection moulding process

\begin{tabular}{|l|c|c|}
\hline \multicolumn{1}{|c|}{ Conditions } & $\begin{array}{c}\text { Conventional } \\
\text { injection moulding }\end{array}$ & $\begin{array}{c}\text { Mucell }^{\circledR} \text { (foam) } \\
\text { injection moulding }\end{array}$ \\
\hline Injection pressure & $1000 \mathrm{bar}$ & $1000 \mathrm{bar}$ \\
\hline Injection temperature & $200^{\circ} \mathrm{C}$ & $200^{\circ} \mathrm{C}$ \\
\hline Injection speed & $35-45 \mathrm{~mm} / \mathrm{sec}$ & $35-45 \mathrm{~mm} / \mathrm{sec}$ \\
\hline Packing pressure & $700 \mathrm{bar}$ & - \\
\hline Packing time & $9.25 \mathrm{sec}$ & - \\
\hline Mould temperature & $24^{\circ} \mathrm{C}$ & $24^{\circ} \mathrm{C}$ \\
\hline Cooling time & $55 \mathrm{sec}$ & $55 \mathrm{sec}$ \\
\hline $\begin{array}{l}\text { Supercritical fluid } \\
\text { (SCF) }\end{array}$ & - & $0.69[\%]$ \\
\hline SCF flow rate & - & $0.19 \mathrm{~kg} / \mathrm{hrs}$ \\
\hline SCF delivery pressure & - & $2800 \mathrm{Psi}$ \\
\hline SCF injection time & - & $3.5 \mathrm{sec}$ \\
\hline
\end{tabular}

Before moulding, all materials were dried properly in order to remove the moisture. The samples were moulded at the processing conditions indicated in Table 1. While working with Mucell ${ }^{\circledR}$ process to form the foamed samples, $\mathrm{N}_{2}$ gas was used as the supercritical fluid and inserted inside the barrel during the screw recovery process. After moulding, packing pressure was eliminated to allow the nucleation and subsequent cells growth expands the parts and provides the essential pressure to pack it out against the mould walls [9]. With conventional injection moulding no $\mathrm{N}_{2}$ gas was used and after the moulding, packing pressure was applied. A mould of ASTM standard for tensile, flexural and impact test bars was used.

\subsection{Characterization techniques}

\subsubsection{Scanning electron microscopy (SEM)}

Cryogenically fractured foamed and unfoamed samples surfaces were studied by SEM (Inspect S-570) (FEI Company) and Zeiss EVO 18 instruments. Prior to scanning the fractured surfaces were gold coated. Obtained images were analyzed by ImageJ software.

\subsubsection{Characterization of microcellular foamed samples}

Density measurements of foamed $\left(\rho_{\mathrm{f}}\right)$ and unfoamed $\left(\rho_{\mathrm{u}}\right)$ samples were performed using Alfa Mirage Electronic Densimeter (MD-300S) in which distilled water was used as the reference fluid. For each sample in order to minimize the error density measurement was conducted at least five times and average values were taken. In order to determine the density reduction or void fraction $\left(V_{\mathrm{f}}\right)$ Equation (1) was used while Equation (2) was used to determine the volume expansion ratio $(\phi)[3,5,6,10]$ :
$V_{\mathrm{f}}[\%]=\frac{\rho_{\mathrm{u}}-\rho_{\mathrm{f}}}{\rho_{\mathrm{u}}} \cdot 100$

$\phi=\frac{\rho_{\mathrm{u}}}{\rho_{\mathrm{f}}}=\frac{1}{1-V_{\mathrm{f}}}$

Equation (3) was used to calculate the Foam cell density $\left(N_{\mathrm{f}}\right)[6,10]$ :

$N_{\mathrm{f}}=\left(\frac{n}{A}\right)^{3 / 2} \cdot \phi$

where $A\left(\right.$ in $\left.\mathrm{cm}^{2}\right)$ is the area taken from the SEM images and $n$ represents the number of the cells.

\subsubsection{Mechanical properties}

Tensile test of all the samples were performed according to the ASTM D638 test procedure at the cross head speed of $5 \mathrm{~mm} / \mathrm{min}$ on Instron 3382 instrument. Flexural testing of all compositions were also completed on the same instrument following ASTM D790 test method at the cross head speed of $14 \mathrm{~mm} / \mathrm{min}$. Impacts testing of all the samples were completed as per the ASTM D256 test method on an impact tester ((TMI) model 43-02-01). In order to calculate the specific flexural strength, specific flexural modulus, specific tensile strength, specific tensile modulus, and specific impact strength, the tested flexural strength, flexural modulus, tensile strength, tensile modulus and impact properties were divided by the densities of the respective samples.

\subsubsection{Thermogravimetric analysis (TGA)}

The TGA study was done at $30-600^{\circ} \mathrm{C}$ on TA Instruments (TGA Q-500) analyzer at the rate of $20^{\circ} \mathrm{C} \cdot \mathrm{min}^{-1}$ in a nitrogen atmosphere.

\subsubsection{Differential scanning calorimetry (DSC)}

DSC studies of all foamed and unfoamed injection moulded samples were performed with a TA Instrument (DSC Q-200) analyzer at $10^{\circ} \mathrm{C} / \mathrm{min}$ scan rate and the values from the 1 st heating cycle were reported. The glass transition temperature $\left(T_{\mathrm{g}}\right)$, cold crystallization peak temperature $\left(T_{\mathrm{cc}}\right)$, melting temperature $\left(T_{\mathrm{m}}\right)$, and enthalpy of melting $\left(\Delta H_{\mathrm{m}}\right)$, were analyzed for all the samples using Universal Analysis software from TA Instruments. Percentage crystallinities of all the samples were calculated using Equation (4):

$X_{\mathrm{c}}=\frac{\Delta H_{\mathrm{m}}-\Delta H_{\mathrm{cc}}}{\Delta H_{\mathrm{m}^{\circ}}} \cdot \frac{100}{W_{\mathrm{f}}}$ 
where $X_{\mathrm{c}}$ is the crystallinity [\%], $\Delta H_{\mathrm{m}}$ the heat of melting, $\Delta H_{\mathrm{cc}}$ the heat of cold crystallization, $\Delta H_{\mathrm{m}^{\circ}}$ heat of melting of $100 \%$ crystalline PLA samples (considered as $\Delta H_{\mathrm{m}^{\circ}}=93 \mathrm{~J} / \mathrm{g}$ ), and $W_{\mathrm{f}}$ the PLA weight fraction in the composite $[11,12]$. From the DSC cold crystallization peak, slope of the peak $\left(S_{\mathrm{p}}\right)$ (at lower temperature side) as a measure of rate of crystallization and peak width at a half height $\left(\Delta W_{\mathrm{d}}\right)$ as a measure of crystallite size distribution were also calculated. A schematic, representing parameters evaluated from DSC cold crystallization peak is presented in Figure 1 [13].

\subsubsection{Heat deflection temperature (HDT)}

In order to determine the HDT of all foamed and unfoamed samples dynamic mechanical analyzer of the TA instrument (DMA Q-800) was used. The sam-

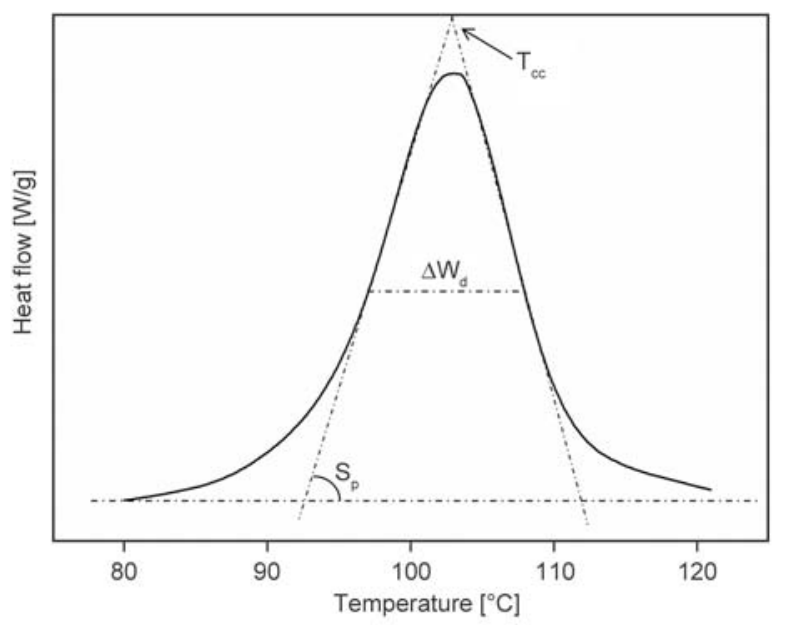

Figure 1. Schematic representation of DSC cold crystallization peak parameters

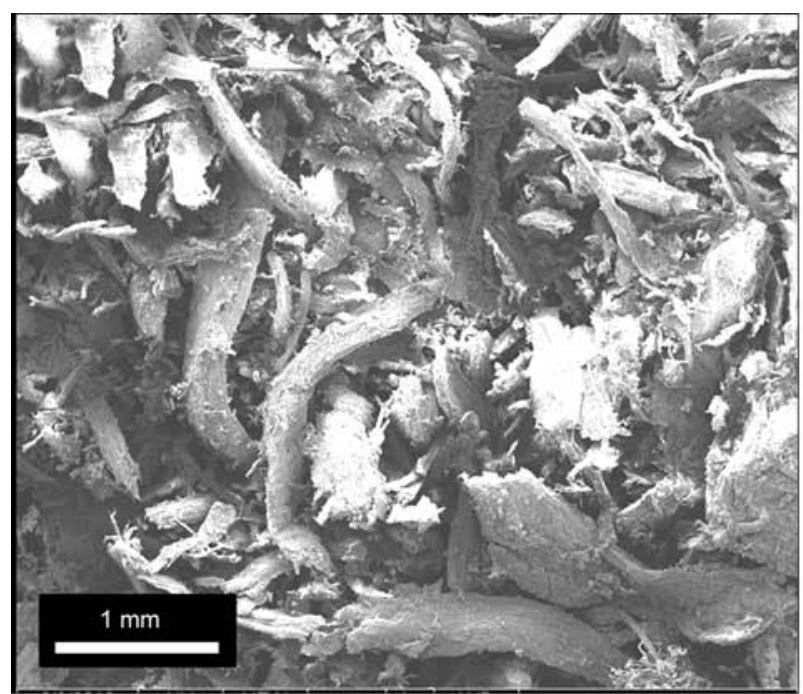

a) ples were prepared in the form of rectangular bars of dimensions $50 \times 3.2 \times 12.8 \mathrm{~mm}^{3}$. The tests were conducted at three point bending mode using a load of 66 psi $(0.455 \mathrm{MPa})$. During the test samples were heated from 30 to $70^{\circ} \mathrm{C}$ at a rate of $2^{\circ} \mathrm{C} / \mathrm{min}$. HDT is the temperature at which deflection of $0.25 \mathrm{~mm}$ occurred for a given sample at specified conditions as per ASTM D648 test method [14].

\section{Results and discussion}

\subsection{Morphology study by SEM}

\subsubsection{Microstructure of the composites}

The SEM images of the willow-fiber are shown in Figure 2. It can be observed from the figure that the willow-fiber are in the form of bundles of small fibers with dimension ranging between 500-2000 $\mu \mathrm{m}$ in length and $250-300 \mu \mathrm{m}$ in diameter with rough surface morphology. The fractured surfaces of the composites were viewed to analyze the mechanism of failure and the possible interaction between PLA matrix and willow-fiber.

The fractured surfaces of PLA/willow-fiber (80/20) and (70/30) composites are shown in Figure 3. SEM images revealed uniform distribution of fibers in both the composites. Many voids inside the matrix as well as spaces between willow-fiber and polymer matrix were observed. Voids inside the matrix might have been generated because of the removal of the willow-fiber at the time of cryogenic fracture of the samples. Both observations, voids inside the matrix and spaces between willow-fiber and PLA matrix suggest insufficient bonding between the surface of willow-fiber and PLA matrix [15].

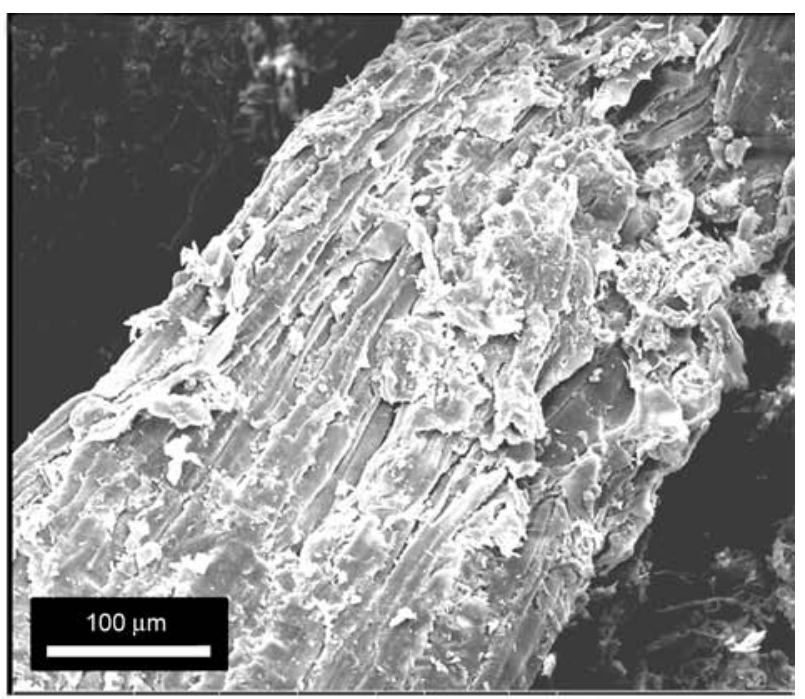

b)

Figure 2. Structure and appearance of willow-fiber: (a) overview; (b) detailed view 


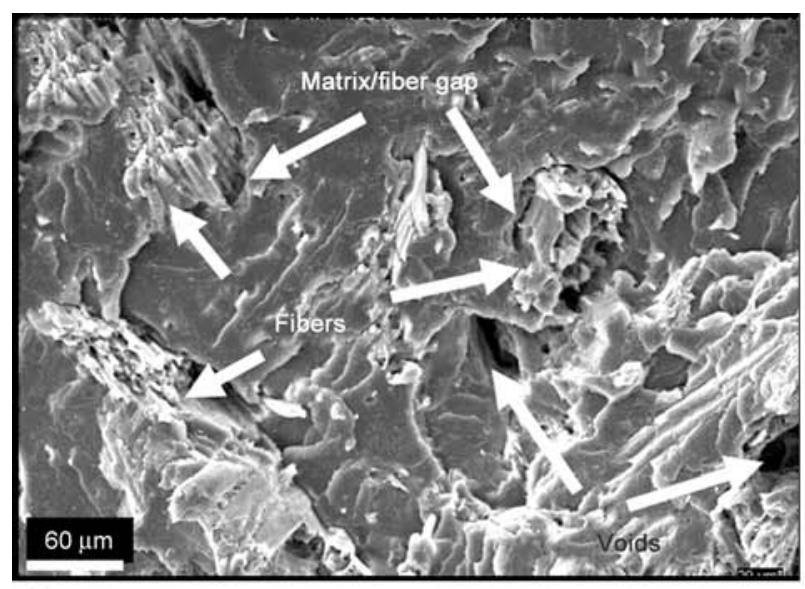

a)

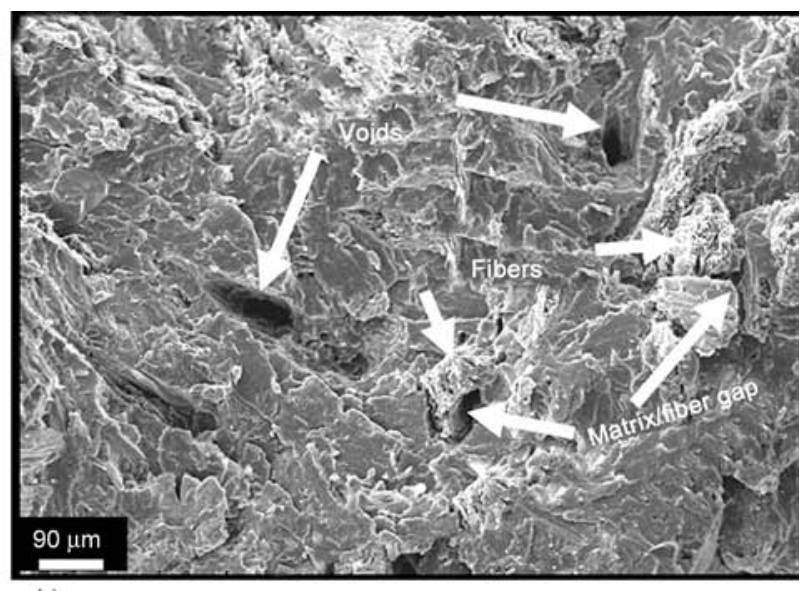

b)

Figure 3. SEM images of the cryogenically fractured unfoamed composite surfaces: (a) PLA/willow-fiber (80/20); (b) PLA/willow-fiber (70/30)

\subsubsection{Morphology of microcellular foamed samples}

SEM images of the microcellular foam structure of PLA and composites are shown in Figure 4. Morphology analysis of the microcellular foams was done by imageJ software. Foamed samples of all composites samples show cells with the finer average sizes in comparison to those of virgin and extruded PLA. Figure 5 shows the comparison of cell size and cell densities of these foamed samples. The cell-size reduced in case of extruded PLA as compared to virgin PLA and thereafter further reduced on addition of willow-fiber. The cell-density increased in case of foamed samples of extruded PLA as compared to those of virgin PLA. It further enhanced in case of composites as the willow-fiber content increased.

As the PLA was extruded, its DSC data (Table 2) show that crystallinity [\%] increased but crystallite sized reduced and distribution narrowed down in comparison to neat PLA. This in turn gave rise to increased preferable sites for the nucleation at the interface of the crystallites for foaming. As a result the nucleation density increased significantly leading to higher cell density. But since nucleation density was higher, average cell size reduced due to less space available for the expansion.

In case of composites the heterogeneous nucleation increased the nucleation sites resulting in the enhanced cell-density. However, due to increased melt viscosity of the matrix, on increasing the willow-fiber content, the composite turned stiffer than the unfilled PLA. Therefore, the cell-growth became difficult which led to the reduced average cell size. Resistance in the cell growth due to increased melt viscosity and stiffness of matrix after adding the wood-flour/cellulose-fibers has also been reported elsewhere [3, 16-20].

Figure 6 illustrates the variations of void fraction (Equation (1)) and expansion ratio (Equation (2)) of the foamed samples. The void fraction and the expansion ratio of the extruded PLA increased in comparison of virgin PLA significantly. This may be explained on the basis of higher nucleation density leading to higher cell density and reduced average cell size as discussed above. The cumulative effect of both the factors is exhibited in the form of increased void fraction and expansion ratio.

On the contrary, the void fraction and expansion ratio decreased in the case of composites on increasing the filler content. This trend may be expected as the volume expansion ratio and the void fraction during the foaming process is controlled by not only the number of the nucleated cells but also the amount of gas dissolved in the matrix [3,16-20]. Previous studies have established that increasing the filler content results in the decrease of the volume fraction of the matrix in composites [21]. As a result the amount of gas absorbed in composites noticeably lowered in comparison of neat PLA. Hence the decreasing trend in the void fraction and the volume expansion ratio is resulted.

\subsection{Mechanical properties}

In Figure 7 the specific flexural strength and specific flexural modulus while in Figure 8, specific tensile strength and specific tensile modulus are shown. Figure $7 \mathrm{a}$ and $8 \mathrm{a}$, exhibited that addition of willowfiber caused reduction in specific flexural strength and in specific tensile strength of all unfoamed 


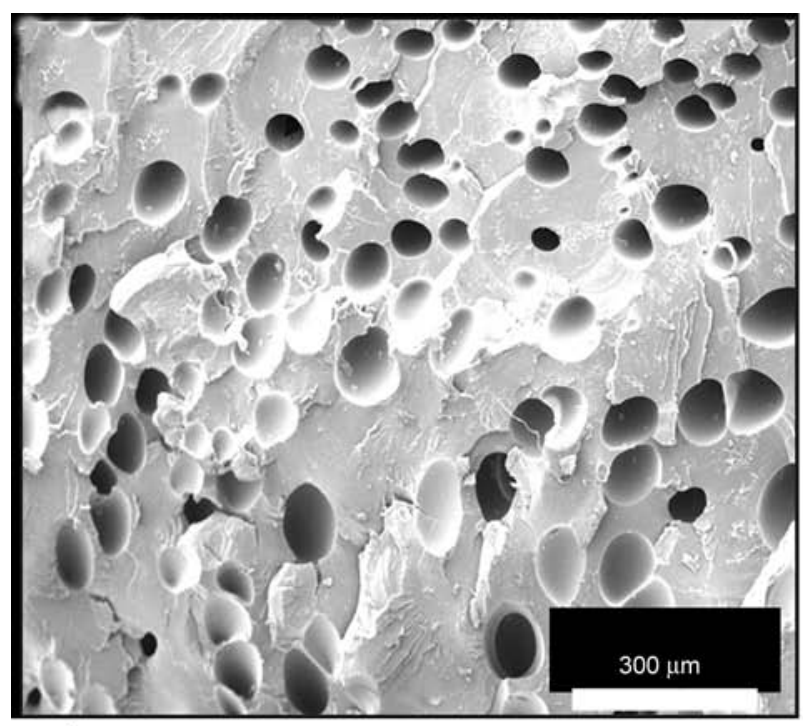

a)

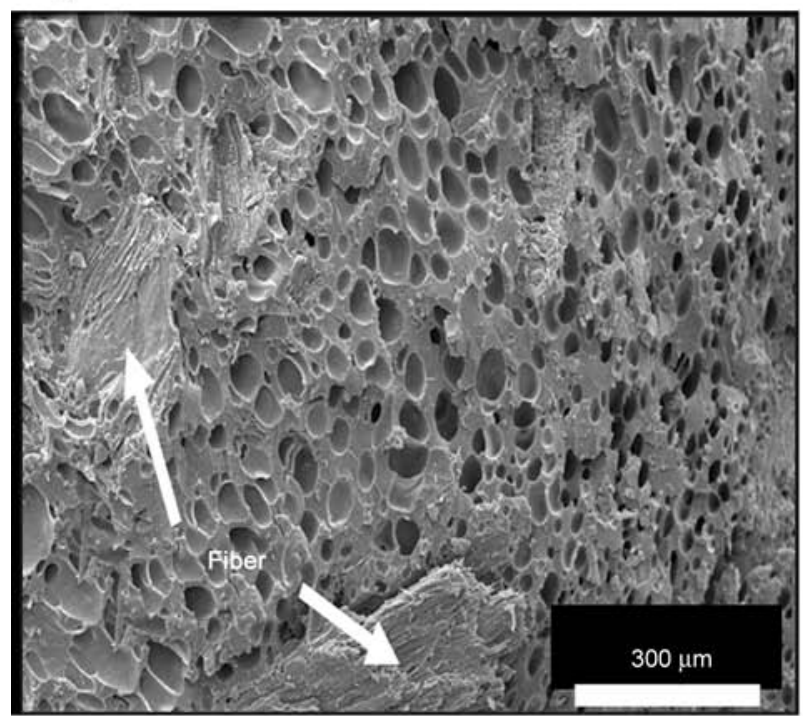

c)

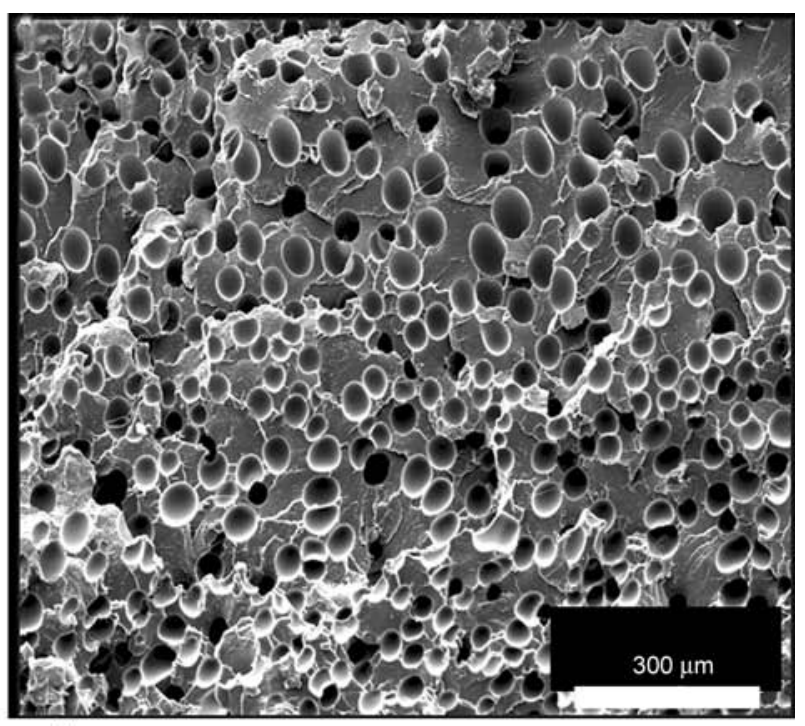

b)

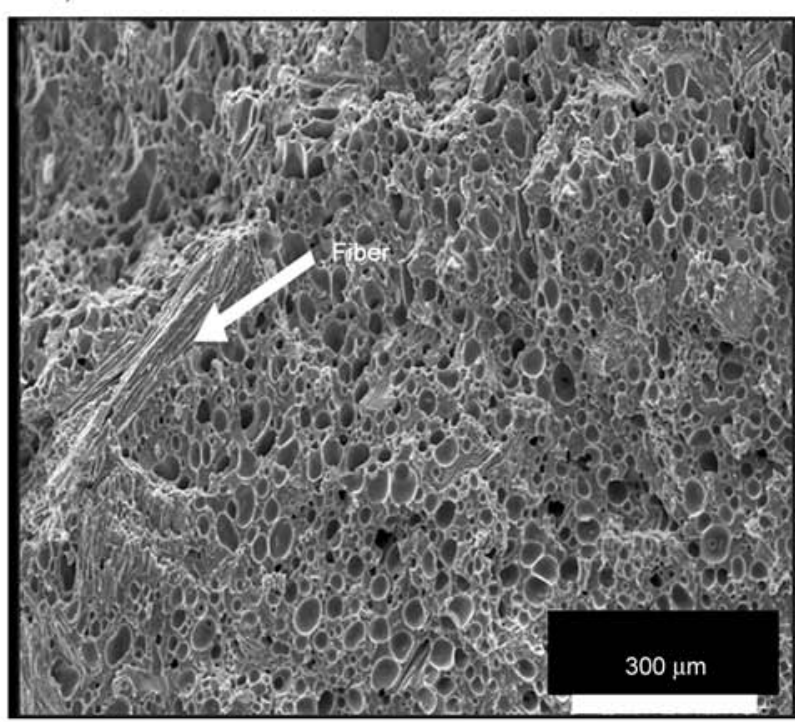

d)

Figure 4. Scanning electron microscopy (SEM) image of foamed samples: (a) virgin PLA; (b) extruded PLA; (c) PLA/willow-fiber (80/20); (d) PLA/willow-fiber (70/30)

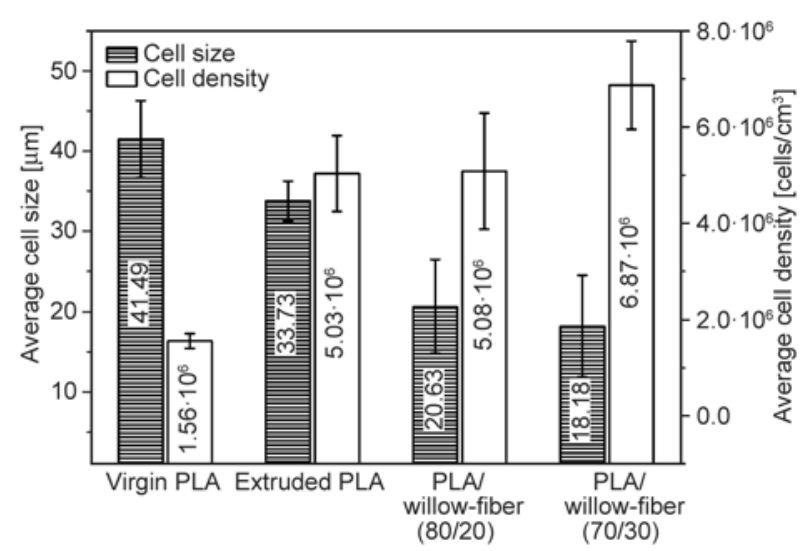

Figure 5. Effect of willow-fiber content on the cell size and cell density of foamed PLA and composites

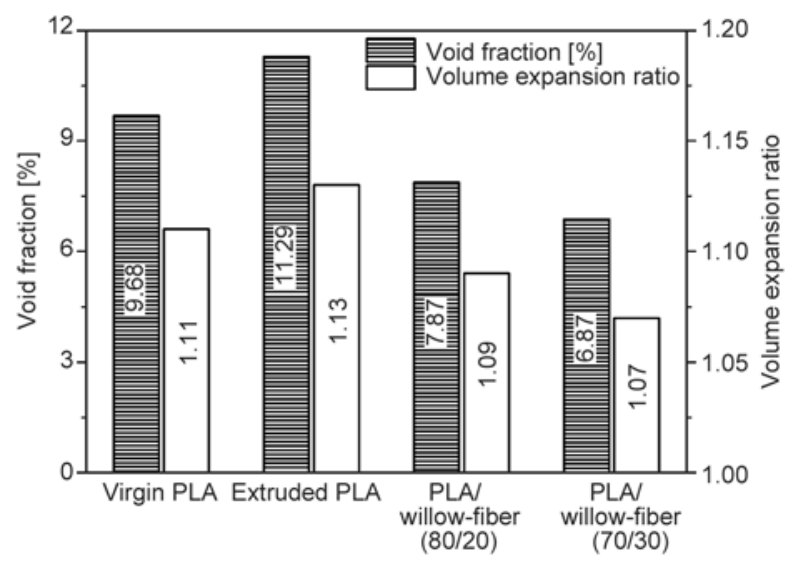

Figure 6. Effect of willow-fiber content on the void fraction and volume expansion ratio of foamed PLA and composite 
Table 2. DSC data of PLA and PLA based foamed and unfoamed composites

\begin{tabular}{|l|l|c|c|c|c|c|c|c|c|}
\hline \multicolumn{1}{|c}{ Sample name } & $\begin{array}{c}\text { Sample } \\
\text { type }\end{array}$ & $\begin{array}{c}\boldsymbol{S}_{\mathbf{p}} \\
{\left[\mathbf{W} /\left(\mathbf{g} \cdot{ }^{\circ} \mathbf{C}\right)\right]}\end{array}$ & $\begin{array}{c}\Delta \boldsymbol{W}_{\mathbf{d}} \\
{\left[{ }^{\circ} \mathbf{C}\right]}\end{array}$ & $\begin{array}{c}\boldsymbol{T}_{\mathbf{g}} \\
{\left[{ }^{\circ} \mathbf{C}\right]}\end{array}$ & $\begin{array}{c}\boldsymbol{T}_{\mathbf{c c}} \\
{\left[{ }^{\circ} \mathbf{C}\right]}\end{array}$ & $\begin{array}{c}\boldsymbol{H}_{\mathbf{c c}} \\
{[\mathbf{J} / \mathbf{g}]}\end{array}$ & $\begin{array}{c}\boldsymbol{T}_{\mathbf{m}} \\
{\left[{ }^{\circ} \mathbf{C}\right]}\end{array}$ & $\begin{array}{c}\boldsymbol{H}_{\mathbf{m}} \\
{[\mathbf{J} / \mathbf{g}]}\end{array}$ & $\begin{array}{c}\boldsymbol{X}_{\mathbf{c}} \\
{[\mathbf{\%}]}\end{array}$ \\
\hline \multirow{2}{*}{ Virgin PLA } & Unfoamed & 0.014 & 20.56 & 62.98 & 104.87 & 28.83 & 169.10 & 45.50 & 17.92 \\
\cline { 2 - 12 } & Foamed & 0.045 & 10.58 & 62.60 & 103.05 & 27.02 & 169.68 & 45.86 & 20.26 \\
\hline \multirow{2}{*}{ Extruded PLA } & Unfoamed & 0.017 & 14.55 & 62.49 & 98.26 & 26.82 & 169.17 & 48.26 & 23.05 \\
\cline { 2 - 12 } & Foamed & 0.039 & 10.76 & 62.85 & 98.06 & 24.11 & 169.14 & 49.17 & 26.95 \\
\hline \multirow{2}{*}{ PLA/willow-fiber (80/20) } & Unfoamed & 0.054 & 8.50 & 66.29 & 96.59 & 25.68 & 169.54 & 43.97 & 24.58 \\
\cline { 2 - 12 } & Foamed & 0.073 & 7.98 & 64.45 & 95.00 & 24.30 & 169.07 & 45.80 & 28.90 \\
\hline \multirow{2}{*}{ PLA/willow- fiber (70/30) } & Unfoamed & 0.058 & 8.10 & 66.41 & 95.38 & 21.89 & 168.81 & 40.61 & 28.76 \\
\cline { 2 - 12 } & Foamed & 0.066 & 7.86 & 64.15 & 95.17 & 19.87 & 168.55 & 41.32 & 32.95 \\
\hline
\end{tabular}

PLA/willow-fiber composites. This reduction in strength of unfoamed composites may be due to the poor stress transfer across the fiber-matrix interphase which suggested weak interfacial bonding between willow-fiber and PLA matrix. Similar observation was reported elsewhere [22]. Further, the foamed composites showed decreased specific flexural strength and specific tensile strength in every instance when compared with their unfoamed counterparts. This decrease in specific flexural strength

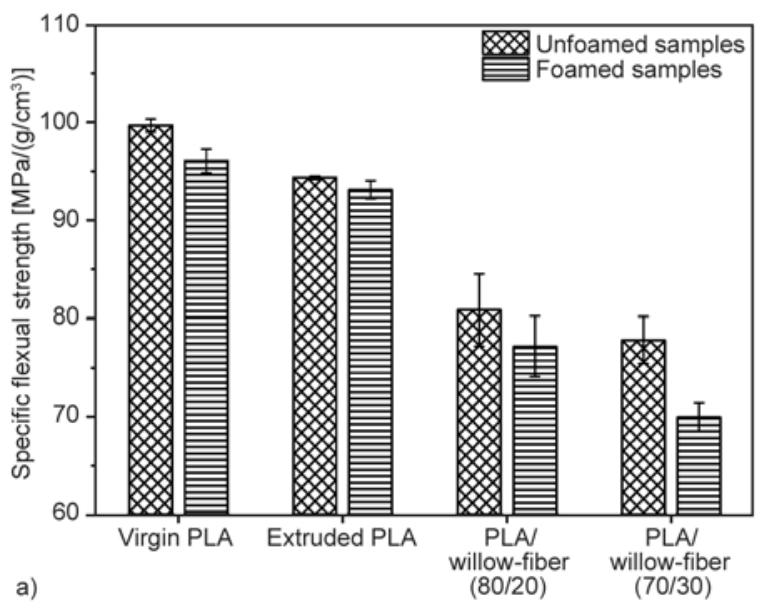

and in specific tensile strength of the foamed composites might be because of the presence of cells inside the matrix. Presumably, these cells become points of stress concentration which decreased the strength of the foamed composites. Similar observation has also been reported earlier [8]. The results of specific flexural modulus and specific tensile modulus (Figure $7 \mathrm{~b}$ and $8 \mathrm{~b}$ ) indicate that the addition of willow-fiber increased the modulus of the unfoamed composites. The specific flexural modulus

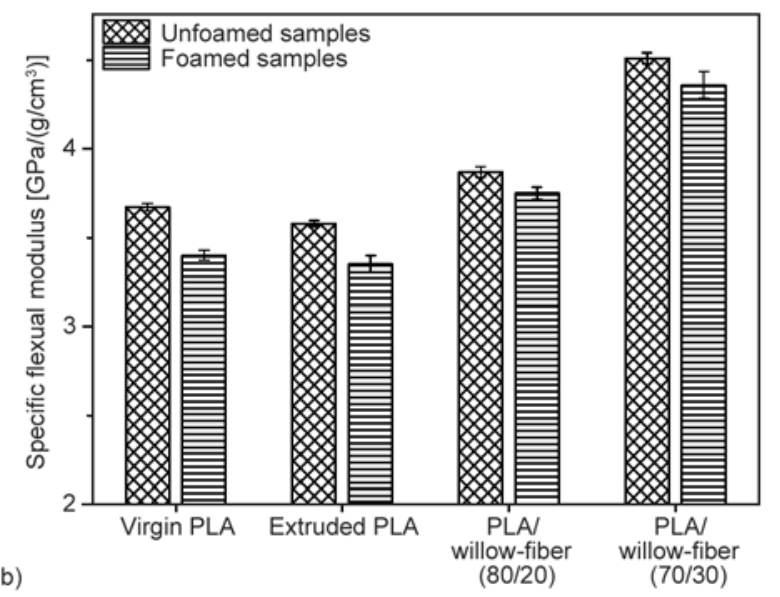

Figure 7. Mechanical properties of the foamed and unfoamed PLA and composites: (a) specific flexural strength; (b) specific flexural modulus
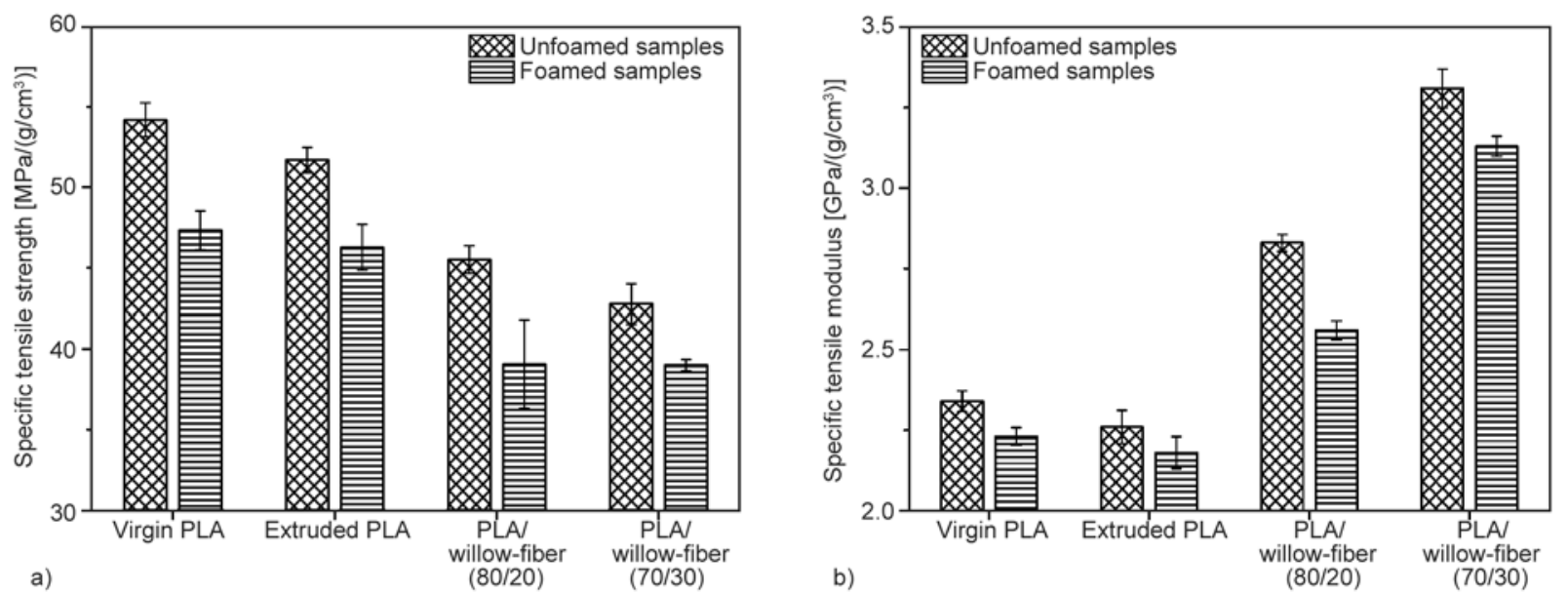

Figure 8. Mechanical properties of the foamed and unfoamed PLA and composites: (a) specific tensile strength; (b) specific tensile modulus 
of unfoamed PLA/willow-fiber (80/20) and (70/30) composites increased by 11.5 and $30 \%$, respectively, whereas the specific tensile modulus of unfoamed PLA/willow-fiber (80/20) and (70/30) composites increased by 21 and $41.4 \%$, respectively, in comparison to unfoamed PLA samples. This increase in the modulus of unfoamed composites may be due to enhanced crystallinity and differential thermal shrinkage. Thus although there may not be good adhesion between willow-fiber and matrix, the modulus increase is shown since the parameters are evaluated at low strains where weakness in the composites structure does not have time to take effect [15, 22, 23].

Further, the specific flexural modulus and specific tensile modulus of the foamed composite reduced slightly in comparison to their unfoamed counterparts. This might be due to the presence of voids or microcells inside the matrix.

The observed decrease in the mechanical properties of unfoamed extruded PLA in comparison to the unfoamed virgin PLA might be because of the molecular weight degradation of extruded PLA during extrusion by shear and thermal exposure. Decrease in molecular weight during extrusion and hence a decrease in mechanical properties has also been reported by some other researchers $[1,24]$.

Figure 9 shows the specific notched impact strength of the foamed and unfoamed samples. As shown, incorporation of willow-fiber decreased the specific notched impact strength of the unfoamed composites. The decrease in specific notched impact strength of unfoamed composites might be because of the increased brittleness of the composites due to the addition of the cellulosic fiber $[15,25,26]$. The specific notched impact strength of the foamed composites show increasing trend when compared with their unfoamed counterparts. There are 15.9 and $45.5 \%$ increment in specific notched impact strength of foamed PLA/willow-fiber (80/20) and (70/30) composites, respectively, in comparison to their

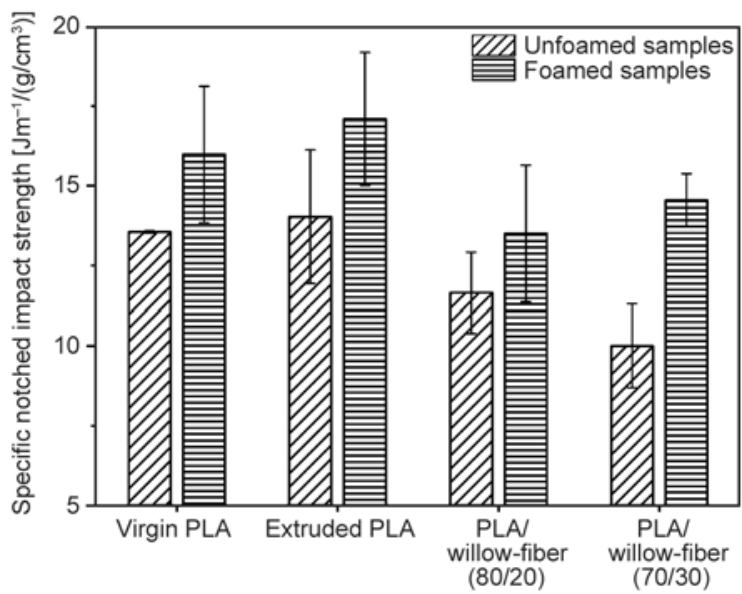

Figure 9. Specific notched impact strength of the foamed and unfoamed PLA and composites

unfoamed counterparts. This increment in the specific notched impact strength of the foamed composites was due to the presence of micro cells which help in preventing the crack propagation process and absorb the energy thus increased the total energy required to propagate the crack. Further it may be assumed that during crack propagation cell walls of the foams also absorbed the energy and thus total impact strength increased [5].

\subsection{Thermogravimetric analysis (TGA)}

TGA was done to study the effect of temperature on the stability of foamed and unfoamed PLA and the composites. The results are shown in Table 3. The TGA curve of willow-fiber shows slight degradation near $100^{\circ} \mathrm{C}$ due to moisture loss followed by severe single stage degradation starting at $310^{\circ} \mathrm{C}$. From the TGA results it is evident that addition of willow-fiber decreases the thermal stability of the composites which might be due to the decrease in the relative molecular mass of PLA after adding the willow-fiber [27]. When the thermal stability of the foamed samples are compared with their unfoamed counterparts, it is observed that in case of virgin and extruded PLA foamed samples have almost the same thermal stability as the unfoamed samples. In case

Table 3. TGA data of PLA and PLA based foamed and unfoamed composites

\begin{tabular}{|c|c|c|c|c|c|c|}
\hline \multirow[t]{2}{*}{ Sample name } & \multicolumn{2}{|c|}{$\begin{array}{l}\text { Onset temperature } \\
\qquad\left[{ }^{\circ} \mathrm{C}\right]\end{array}$} & \multicolumn{2}{|c|}{$\begin{array}{c}\text { Inflection temperature } \\
\qquad\left[{ }^{\circ} \mathrm{C}\right]\end{array}$} & \multicolumn{2}{|c|}{$\begin{array}{c}\text { End temperature } \\
{\left[{ }^{\circ} \mathrm{C}\right]}\end{array}$} \\
\hline & Unfoamed & Foamed & Unfoamed & Foamed & Unfoamed & Foamed \\
\hline Willow-fiber & \multicolumn{2}{|c|}{310} & \multicolumn{2}{|c|}{365} & \multicolumn{2}{|c|}{381} \\
\hline Virgin PLA & 335 & 336 & 352 & 353 & 362 & 363 \\
\hline Extruded PLA & 334 & 335 & 352 & 353 & 363 & 364 \\
\hline PLA/Willow-fiber $(80 / 20)$ & 329 & 313 & 349 & 335 & 362 & 347 \\
\hline PLA/Willow-fiber (70/30) & 313 & 303 & 330 & 320 & 344 & 337 \\
\hline
\end{tabular}


of the composites, foamed samples show lower thermal stability than the corresponding unfoamed samples which might be due to the decrease in the interfacial bonding between fibers and matrix during the foaming.

\subsection{Crystallization study by DSC}

Crystallization studies were carried out on foamed and unfoamed samples of PLA and the composites by DSC and the data obtained there from are shown in Table 2. The crystallinity [\%] of the extruded PLA increased in comparison to virgin PLA. The slope of the cold crystallization peak indicated the increase in the rate of crystallization $\left(S_{\mathrm{p}}\right)$ in case of extruded PLA as compared to virgin PLA while width of peak at half height $\left(\Delta W_{\mathrm{d}}\right)$ showed the narrowing down the crystallites size distribution in the former one in comparison to the latter. This happened due to decrease in molecular weight because of thermal degradation and chain scission during extrusion process [1].

The $T_{\mathrm{g}}$ and $T_{\mathrm{m}}$ of the PLA (virgin and extruded) and the composite samples were not appreciably changed, however, the percentage crystallinity increased on increasing the willow-fiber content. The rate of cold crystallization also increased on increasing willowfiber content as revealed by the slope of the cold crystallization peak. Higher slope denoted higher rate of crystallization while lower slope signified the lower rate of crystallization [13]. The cold crystallization peak was shifted towards left on increasing willowfiber content showing the decrease in $T_{\mathrm{cc}}$. The area of cold crystallization peak was also decreased in the similar manner on increasing willow-fiber content, which implies that $X_{\mathrm{c}}[\%]$ increases on increasing willow-fiber content. The $\Delta W_{\mathrm{d}}$ of cold crystallization curve decreased on increasing willow-fiber content showing narrowing down of the crystallite size distribution. The above observations clearly indicate that willow-fiber provided crystallization surfaces and enhanced the $X_{\mathrm{c}}[\%]$ in PLA composites. Increased number of crystallites did not allow the crystallites to grow further, however, the resultant crystallinity was increased. As a result the average crystallite size was smaller and more uniform in composites in comparison to those in neat samples. When unfoamed samples were compared to their foamed counterparts the total crystallinity [\%] was found to increase in all foamed samples and the amont of increase was almost similar in all the samples, indicating that the addition of willow-fiber is acting in the similar manner in unfoamed and foamed samples. However, the crystallinity increased in the foamed samples may be due to strain induced alignment of the PLA chains during the cell growth process. Wang et al. [28] have also reported improvement in the crystallinity of PLA due to the extension associated with the cell growth during foaming.

\subsection{Heat deflection temperature (HDT)}

HDT of PLA and PLA based foamed and unfoamed composites are shown in Table 4. HDT is the short term thermal characteristic which is the measure of the thermal sensitivity and stability of polymeric materials. The results show that addition of willowfiber increased HDT of the unfoamed composites. On addition of $20 \%$ willow-fiber, HDT increased to $58.7^{\circ} \mathrm{C}$, while on addition of $30 \%$ willow-fiber the same was increased to $60.3^{\circ} \mathrm{C}$. This improvement in HDT is due to reinforcing effect of willow-fiber in PLA matrix as well as due to increased crystallinity (Table 2). Huda et al. [29] also studied the similar improvement in HDT while studying the reinforcement of PLA using wood-fiber at 30 and $40 \mathrm{wt} \%$ loading.

HDT of foamed samples are found to be the same to their unfoamed counterparts which indicates no effect of foaming on HDT.

Although the increase in HDT depends upon the crystallinity and reinforcement effect of the filler, yet the improvement in HDT, in present study, is not as much as speculated, which may because of insufficient interfacial interactions between PLA and willow-fiber as obvious from SEM image (Figure 3). Still the improvement in HDT values on addition of willow-fiber can be regarded as an important achievement which indicates the increased upper working temperature limit of the composites.

Table 4. HDT data of PLA and PLA based foamed and unfoamed composites

\begin{tabular}{|l|c|c|}
\hline \multirow{2}{*}{\multicolumn{1}{|c|}{ Samples name }} & \multicolumn{2}{c|}{$\begin{array}{c}\text { HDT } \\
{\left[{ }^{\circ} \mathbf{C}\right]}\end{array}$} \\
\cline { 2 - 3 } & Unfoamed sample & Foamed sample \\
\hline Virgin PLA & $56.5 \pm 0.10$ & $56.2 \pm 0.11$ \\
\hline Extruded PLA & $56.7 \pm 0.14$ & $56.5 \pm 0.25$ \\
\hline PLA/willow-fiber (80/20) & $58.7 \pm 0.22$ & $58.7 \pm 0.14$ \\
\hline PLA/willow-fiber (70/30) & $60.3 \pm 0.14$ & $60.1 \pm 0.25$ \\
\hline
\end{tabular}




\section{Conclusions}

The PLA/willow-fiber biocomposites were prepared in twin screw extruder and subsequently injection molded by two separate processes; one by conventional injection molding without foaming module and the other with the foaming module on the same injection molding machine. The key findings are as below:

- The morphology study shows voids inside the matrix and weak phase interaction between PLA matrix and willow-fiber. SEM images of the foamed sample show that the addition of willow-fiber in the PLA matrix decreased the cell size with increase in the cell density.

- Adding willow-fiber caused a reduction in specific flexural strength and in specific tensile strength of all foamed and unfoamed PLA/willow-fiber composites. However, addition of willow-fiber increased the specific tensile modulus and specific flexural modulus of the unfoamed composites which were found maximum at $30 \mathrm{wt} \%$ willow-fiber content. Specific notched impact strength of the foamed composites show increasing trend. Foamed PLA/ willow-fiber (80/20) and (70/30) composites shows 15.9 and $45.5 \%$ improvement in specific notched impact strength respectively compared to their unfoamed counterparts.

- Thermogravimetric analysis shows that the addition of willow-fiber as well as foaming decreased the thermal stability of the composites. DSC results show that addition of willow-fiber in the PLA matrix increased the crystallinity [\%] and crystallization rate while decreased the cold crystallization peak temperature and gave narrower crystallite size distribution. Crystallization properties of the foamed samples were found similar to their unfoamed counterparts.

- HDT improved by $2.2^{\circ} \mathrm{C}$ on addition of $20 \%$ willow-fiber while the same was increased by $3.8^{\circ} \mathrm{C}$ on adding $30 \%$ willow-fiber. Foamed composites show HDT similar to their unfoamed counterparts.

\section{Acknowledgements}

The authors thank the Department of Foreign Affairs and International Trade Canada (DFAIT) and Canadian Bureau for International Education (CBIE) for Providing Fellowship under Canadian Commonwealth Exchange Program, AsiaPacific (Formerly GSEP) 2011-2012 to Mohammad Tahir
Zafar. The Council of Scientific and Industrial Research (CSIR), New Delhi, India (File No.09/086(0913)/2008EMR-I) is acknowledged for providing a senior research fellowship (SRF) to Mohammad Tahir Zafar. The authors are also thankful to the Ontario Research Fund Round 4; Highly Qualified Personnel (HQP) Scholarship from Ontario Ministry of Agriculture, Food and Rural Affairs (OMAFRA), 2009, Ontario, Canada to Nima Zarrinbakhsh; OMAFRAAlternative Renewable Fuels Plus Research Program, 2008, Ontario, Canada. Authors also gives thank to Dr. Naresh V Thevathasan, University of Guelph and Dr. Andrew Gordon, University of Guelph for providing willow-fiber samples.

\section{References}

[1] Carrasco F., Pagès P., Gámez-Pérez J., Santana O. O., Maspoch M. L.: Processing of poly(lactic acid): Characterization of chemical structure, thermal stability and mechanical properties. Polymer Degradation and Stability, 95, 116-125 (2010).

DOI: $10.1016 /$ j.polymdegradstab.2009.11.045

[2] Lim L-T., Auras R., Rubino M.: Processing technologies for poly(lactic acid). Progress in Polymer Science, 33, 820-852 (2008). DOI: 10.1016/j.progpolymsci.2008.05.004

[3] Matuana L. M., Faruk O.: Effect of gas saturation conditions on the expansion ratio of microcellular poly(lactic acid)/wood-flour composite. Express Polymer Letters, 4, 621-631 (2010). DOI: 10.3144/expresspolymlett.2010.77

[4] Zhang Q., Shi L., Nie J., Wang H., Yang D.: Study on poly(lactic acid)/natural fibers composites. Journal of Applied Polymer Science, 125, E526-E533 (2012). DOI: 10.1002/app.36852

[5] Matuana L. M.: Solid state microcellular foamed poly (lactic acid): Morphology and property characterization. Bioresource Technology, 99, 3643-3650 (2008). DOI: 10.1016/j.biortech.2007.07.062

[6] Kohlhoff D., Ohshima M.: Open cell microcellular foams of polylactic acid (PLA)-based blends with semiinterpenetrating polymer networks. Macromolecular Materials and Engineering, 296, 770-777 (2011). DOI: 10.1002/mame.201000371

[7] Anne B., Benezet J. C.: Natural fibre-reinforced biofoams. International Journal of Polymer Science, 2011, 569871/1-569871/14 (2011). DOI: $10.1155 / 2011 / 569871$

[8] Kramschuster A., Gong S., Turng L-S., Li T., Li T.: Injection-molded solid and microcellular polylactide and polylactide nanocomposites. Journal of Biobased Materials and Bioenergy, 1, 37-45 (2007).

DOI: $10.1166 / \mathrm{jbmb} .2007 .004$

[9] Gong S., Yuan M., Chandra A., Kharbas H., Osorio A., Turng L. S.: Microcellular injection molding. International Polymer Processing, 20, 202-214 (2005).

DOI: $10.3139 / 217.1883$ 
[10] Hwang S-S., Hsu P. P., Yeh J-M., Chang K-C., Lai Y-Z.: The mechanical/thermal properties of microcellular injection-molded poly-lactic-acid nanocomposites. Polymer Composites, 30, 1625-1630 (2009). DOI: $10.1002 /$ pc. 20736

[11] Tábi T., Égerházi A. Z., Tamás P., Czigány T., Kovács J. G.: Investigation of injection moulded poly(lactic acid) reinforced with long basalt fibres. Composites Part A: Applied Science and Manufacturing, 64, 99-106 (2014). DOI: 10.1016/j.compositesa.2014.05.001

[12] Battegazzore D., Bocchini S., Frache A.: Crystallization kinetics of poly(lactic acid)-talc composites. Express Polymer Letters, 5, 849-858 (2011). DOI: $10.3144 /$ expresspolymlett.2011.84

[13] Sewda K., Maiti S. N.: Crystallization and melting behavior of HDPE in HDPE/teak wood flour composites and their correlation with mechanical properties. Journal of Applied Polymer Science, 118, 2264-2275 (2010).

DOI: 10.1002/app.30551

[14] Zarrinbakhsh N., Misra M., Mohanty A. K.: Biodegradable green composites from distiller's dried grains with solubles (DDGS) and a polyhydroxy (butyrate-co-valerate) (PHBV)-based bioplastic. Macromolecular Materials and Engineering, 296, 1035-1045 (2011).

DOI: $10.1002 /$ mame.201100039

[15] Mathew A. P., Oksman K., Sain M.: Mechanical properties of biodegradable composites from poly lactic acid (PLA) and microcrystalline cellulose (MCC). Journal of Applied Polymer Science, 97, 2014-2025 (2005). DOI: 10.1002/app.21779

[16] Matuana L. M., Park C. B., Balatinecz J. J.: Processing and cell morphology relationships for microcellular foamed PVC/wood-fiber composites. Polymer Engineering and Science, 37, 1137-1147 (1997). DOI: $10.1002 /$ pen. 11758

[17] Li Q., Matuana L. M.: Foam extrusion of high density polyethylene/wood-flour composites using chemical foaming agents. Journal of Applied Polymer Science, 88, 3139-3150 (2003). DOI: 10.1002/app.12003

[18] Mengeloglu F., Matuana L. M.: Foaming of rigid PVC/ wood-flour composites through a continuous extrusion process. Journal of Vinyl and Additive Technology, 7, 142-148 (2001).

DOI: $10.1002 / \mathrm{vnl} .10282$

[19] Matuana L. M., Mengeloglu F.: Manufacture of rigid PVC/wood-flour composite foams using moisture contained in wood as foaming agent. Journal of Vinyl and Additive Technology, 8, 264-270 (2002). DOI: $10.1002 / \mathrm{vnl} .10373$
[20] Matuana L. M., Li Q.: Statistical modeling and response surface optimization of extruded HDPE/wood-flour composite foams. Journal of Thermoplastic Composite Materials, 17, 185-199 (2004). DOI: $10.1177 / 0892705704035404$

[21] Matuana-Malanda L., Park C. B., Balatinecz J. J.: Characterization of microcellular foamed PVC/cellulosicfibre composites. Journal of Cellular Plastics, 32, 449469 (1996). DOI: $10.1177 / 0021955 X 9603200503$

[22] Bledzki A. K., Gassan J.: Composites reinforced with cellulose based fibres. Progress in Polymer Science, 24, 221-274 (1999).

DOI: $10.1016 / \mathrm{S} 0079-6700(98) 00018-5$

[23] Hedenberg P., Gatenholm P.: Conversion of plastic/cellulose waste into composites. I. Model of the interphase. Journal of Applied Polymer Science, 56, 641-651 (1995).

DOI: 10.1002/app.1995.070560601

[24] Żenkiewicz M., Richert J., Rytlewski P., Moraczewski K., Stepczyńska M., Karasiewicz T.: Characterisation of multi-extruded poly(lactic acid). Polymer Testing, 28, 412-418 (2009).

DOI: $10.1016 /$ j.polymertesting.2009.01.012

[25] Mohanty A. K., Misra M., Hinrichsen G.: Biofibres, biodegradable polymers and biocomposites: An overview. Macromolecular Materials and Engineering, 276-277, 1-24 (2000).

DOI: 10.1002/(sici)1439-2054(20000301)276:1<1::aidmame1>3.0.co;2-w

[26] Ahmad F., Choi H. S., Park M. K.: A review: Natural fiber composites selection in view of mechanical, light weight, and economic properties. Macromolecular Materials and Engineering, 300, 10-24 (2015). DOI: $10.1002 /$ mame.201400089

[27] Yu T., Li Y., Ren J.: Preparation and properties of short natural fiber reinforced poly(lactic acid) composites. Transactions of Nonferrous Metals Society of China, 19, s651-s655 (2009). DOI: $10.1016 /$ S1003-6326(10)60126-4

[28] Wang J., Zhu W., Zhang H. Park C. B.: Continuous processing of low-density, microcellular poly(lactic acid) foams with controlled cell morphology and crystallinity. Chemical Engineering Science, 75, 390-399 (2012). DOI: $10.1016 /$ j.ces.2012.02.051

[29] Huda M. S., Drzal L. T., Misra M., Mohanty A. K.: Wood-fiber-reinforced poly(lactic acid) composites: Evaluation of the physicomechanical and morphological properties. Journal of Applied Polymer Science, 102, 4856-4869 (2006).

DOI: $10.1002 / a p p .24829$ 